\title{
Advanced Nanophotonics: Silicon-Organic Hybrid Technology
}

\author{
Patrick Steglich*, Claus Villringer, Silvio Pulwer, Joachim Bauer, Friedhelm Heinrich, Mauro Casalboni, Sigurd Schrader
}

\begin{abstract}
Integrated photonic devices have gained increasing research interests. Especially silicon photonics have become very attractive for various optical applications. Using silicon-on-insulator as a material platform provides the ability to fabricate photonic devices with electronic devices on a single chip. Driven by substantial research investments, the integration of photonic devices on silicon-on-insulator substrates has reached a degree of maturity that already permits industrial adoption. However, silicon has the disadvantage of linear electro-optical effects, and, therefore, advanced modulation formats are difficult to realize when using silicon-based high-speed modulators. Hence, a new approach was proposed: the silicon-organic hybrid technology. This technology is a viable extension of the silicon-on-insulator material system for efficient highspeed modulation. We herewith present our theoretical and experimental investigations of the silicon-organic hybrid slot-waveguide ring resonator. The advanced device design is described in detail, which allows using both, the efficient silicon-on-insulator strip-waveguides and the silicon-organic hybrid slot-waveguides in single ring resonator. For the first time, we report the transmission spectra of such a resonator covered with an electro-optical polymer.
\end{abstract}

\section{Zusammenfassung}

Integrierte photonische Bauelemente werden in der Forschung immer bedeutender. Besonders die Siliziumphotonik ist für verschiedene optische Anwendungen sehr attraktiv. Die Verwendung von Silizium-auf-IsolatorMaterialsystemen bietet die Möglichkeit, photonische Bauelemente mit elektronischen Geräten auf einem einzelnen Chip zu entwickeln. Durch erhebliche Forschungsinvestitionen hat die photonische Integration auf Silizium-auf-Isolator-Substraten einen Reifegrad, der bereits Industriemaßstäben genügt. Jedoch hat Silizium keinen linearen elektrooptischen Effekt und damit sind moderne Modulationsformate nur schwierig zu realisieren. Daher wird seit eingen Jahren ein neuer Ansatz, die SiliziumOrganik Hybridtechnologie, verfolgt. Diese Technologie ist eine tragfähige Ausdehnung des Silizium-auf-IsolatorMaterialsystems für eine effiziente Hochgeschwindigkeitsmodulation und optische Signalverarbeitung. In diesem Artikel präsentieren wir unsere theoretischen und experimentellen Untersuchungen zu einem Silizium-Organik Hybrid Ringresonator. Das Design und die Herstellung des neuartigen nanophotonischen Bauelements werden im Detail beschrieben. Der demonstrierte Ringresonator kombiniert die Vorteile zweier verschiedener Wellenleiterarten in einem einzelnen Ring, dem verlustarmen Kanal-Wellenleiter und dem Silizium-organischen Hybridschlitzwellenleiter. Wir demonstrieren erstmals ein Transmissionsspektrum eines solchen Ringresonators, der mit einem elektro-optischen Polymer beschichtet ist.

\section{Introduction}

Silicon photonics allows a strong optical confinement of light, due to its high index contrast with most materials, which permits the integration of complex systems with compact footprints. In addition, its compatibility with a complementary metal-oxide-semiconductor (CMOS) process makes this technology attractive from the commercial point of view.

Current electro-optic (EO) modulators are based on semiconductors like silicon or indium phosphide and the fundamental speed limitations are related to carrier injection and removal. Therefore, parametric processes are impaired by non-parametric processes like two-photon absorption and become the main speed-limiting factor. Additionally, silicon has a lack of linear EO coefficients.

During the last decade, a different approach, based on silicon slot-waveguides, has been proposed and experimentally demonstrated to be suitable as optical phase shifter using the linear EO effect (Almeida et al. 2004). Slot-waveguides enable a high field 


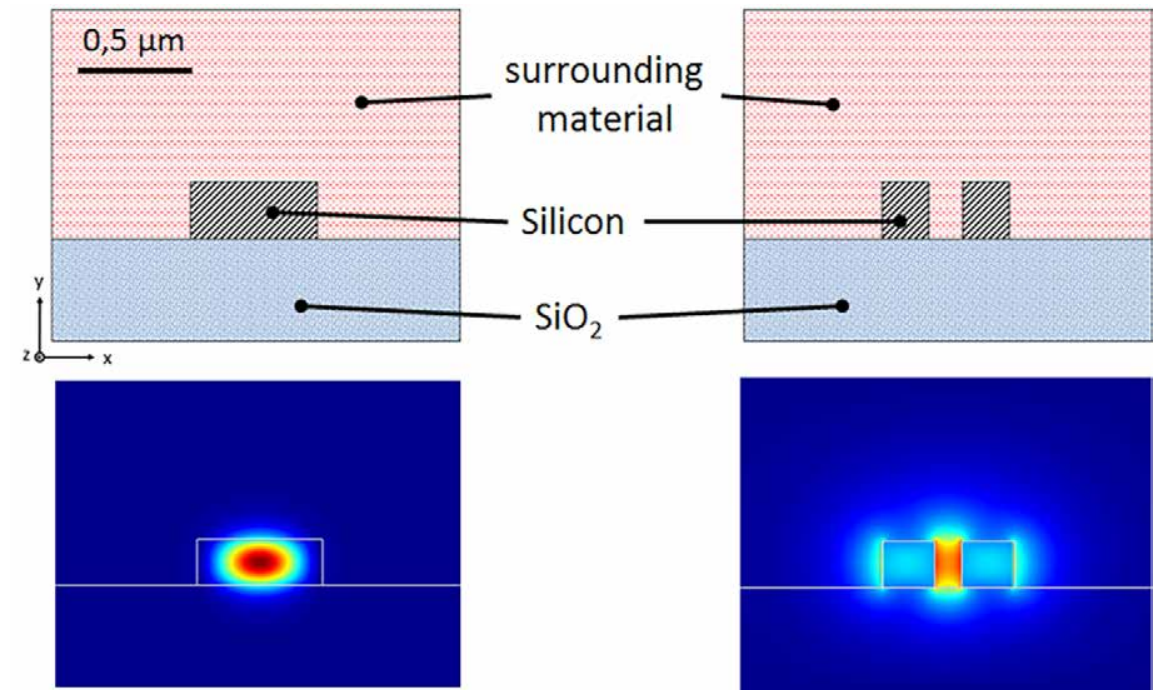

Fig. 1) Guided optical field in a SOI strip-waveguide (left) and in a slot-waveguide (right). The pictures below are showing the confined optical field (Steglich et al. 2015b).
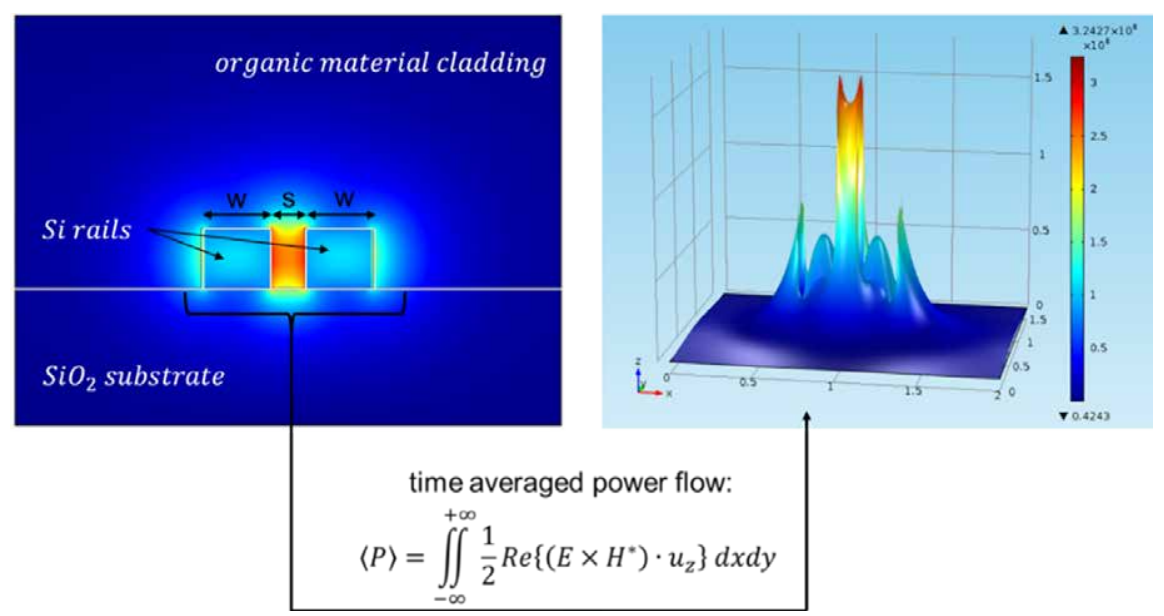

Fig. 2) Cross-sectional view of the quasi-TE mode and the corresponding time averaged power flow profile (Steglich et al. 2015c).

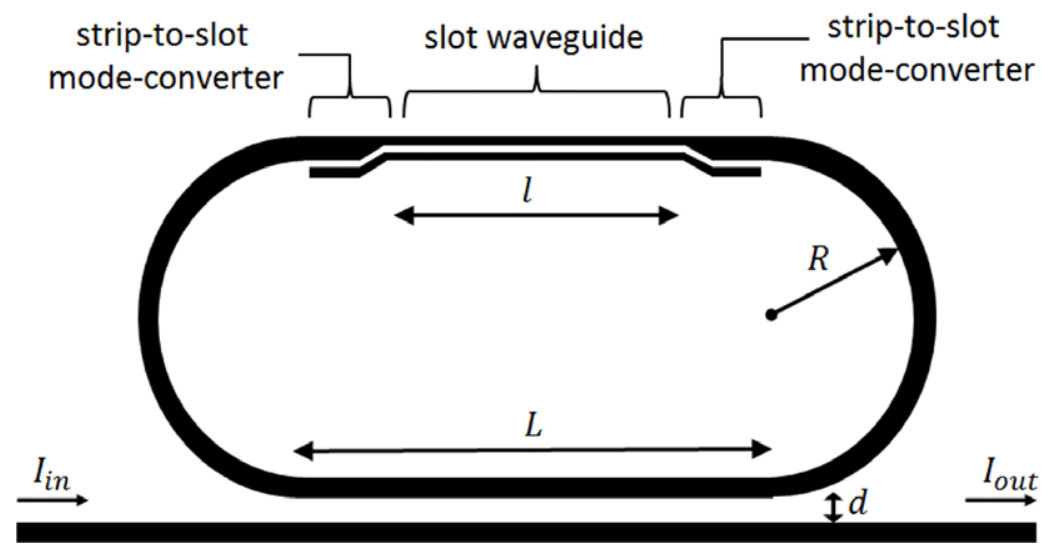

Fig. 3) Schematic of a partially slotted ring resonator (Steglich et al. 2015a) confinement in a narrow region and a high overlap between the optical and the electrical field. Infiltration of the interior of the slot waveguide with an EO organic material allows the use of the Pockels effect. As a consequence, various devices like Mach-Zehnder interferometers and micro-ring resonators have been developed using a slot-waveguide phase shifter (Korn et al. 2014).

The major advantage of slot-waveguides is the fact that the guided light is confined in between two silicon rails. For this reason, the light is forced to interact directly with the surrounding material. The reason for this high confinement in between the silicon rails is the large index contrast of the high index silicon and the low index surrounding material. At the interface, the normal electric field undergoes a large discontinuity, which results in a field enhancement in the low index region with a ratio of the dielectric constant of the surrounding material to that of silicon. A detailed cross-sectional view is depicted in figure 1 and in more detail in figure 2.

The so-called silicon-organic hybrid (SOH) technology is using organic materials, which have exceptional high linear EO coefficients as surrounding material. Slot-waveguides are the key element in order to integrate organic materials in silicon photonics. Because the organic materials offer high linear EO coefficients, one can generate advanced modulation formats (Alloatti et al. 2014). The reason for this is that organic materials have a less free-carrier dispersion, which normally leads to an intrinsic coupling of amplitude and phase.

In the following sections, we describe the design, fabrication and optical characterization of a $\mathrm{SOH}$ ring resonator, which is a promising candidate for future EO modulators using the linear EO effect.

\section{Device Fabrication}

In this section, we describe the design and the fabrication of an integrated ring resonator based on our work published in Steglich et al. (2015a). The device was designed at the University of Applied Sciences, Wildau, and realized in IHP on $200 \mathrm{~nm}$ sili- 


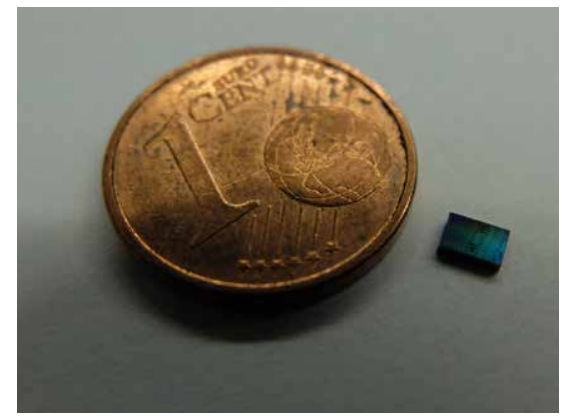

Fig. 4) Photonic chip with over 100 nanophotonic components on an area of $6 \mathrm{~mm}^{2}$.

con-on-insulator wafers using $248 \mathrm{~nm}$ DUV lithography. Because of the potential of the ring resonator getting integrated into IHP's BiCMOS Technology, and, hence, to fabricating it together with driver electronics and Trans Impedance Amplifiers (TIA), the ongoing developments regarding the presented ring resonator are following the IHP's integration concept.

A scheme, the partially slotted ring resonator, is depicted in figure 3 . The hybrid concept of the partially slotted ring resonator takes advantage of a strongly guiding strip waveguide at the bent part of the ring, and of an efficient slot-waveguide at the straight part of the ring. To exploit the advantages of each waveguide type, an efficient strip-to-slot waveguide transition is needed. The length of our strip-loaded slot-waveguide is I $=12 \mu \mathrm{m}$, and the length of the strip-to-slot mode-converter is $8 \mu \mathrm{m}$. With the ring radius $\mathrm{R}=20 \mu \mathrm{m}$, and the coupling length $\mathrm{L}=28 \mu \mathrm{m}$, the total circumference results in $C=182 \mu \mathrm{m}$.

In contrast to our previous work presented in Steglich et al. (2015a), we here use a slot-waveguide without silicon strip-loads. The slot width is $\mathrm{s}=60 \mathrm{~nm}$, and the silicon rail width is $\mathrm{w}=220 \mathrm{~nm}$. Both silicon rails are located on top of a $2 \mu \mathrm{m}$ buried oxide substrate.

A silicon dioxide top cladding is deposited, and a trench etched to open the slot-waveguide structure. This allows for the functionalization of the slot with an organic EO material. Using EO polymers or organic crystals as cladding material, the EO effect, and, therefore, the device tunability is expected to be significantly higher compared to free-carrier plasma dispersion-based phase shifters. Further, the slot-waveguide structure provides a high optical and high electrical confinement, which increases EO effects even more (Steglich et al. 2015c). As cladding material, we spin-coated a side-chain polymer system. The polymer system consists of PMMA and the optical non-linear chromophore Disperse Red 1 (DR1) (IUPAC Name: Poly[(methyl methacrylate)-co-(Disperse Red 1 acrylate)]). After spin-coating, the photonic chip was heated to $60^{\circ} \mathrm{C}$ in an oven for $5 \mathrm{~h}$ in order to remove the solvent. Figure 4 shows the fabricated photonic chip.

\section{Device Characterization}

The transmission spectra of the fabricated device were obtained by a testing platform using a super-luminescent diode as light source. The light was coupled into the silicon waveguides through a fiber grating coupler and out with another fiber grating coupler. Figure 5 shows the photonic chip layout and magnifications of the fiber coupler gratings and ring resonators. We used only TE-polarized light. Figure 6 shows the observed transmission spectrum of the ring resonator.

The achieved Q-factor, which describes the sharpness of the transmission peaks, is about 5000 . This is more than three times smaller compared to the ring resonator without polymer cladding, which was published in (Steglich et al. 2015a). This can be explained by the absorption of the polymer, but also by fabrication imperfections. The full width at half maximum is $F W H M=0.3146 \mathrm{~nm}$, and the free spectrum range is $\mathrm{FSR}=6.7 \mathrm{~nm}$.

\section{Conclusion}

In all, we described the design and fabrication of a novel ring resonator based on slot-waveguide structures combined with strip-waveguide

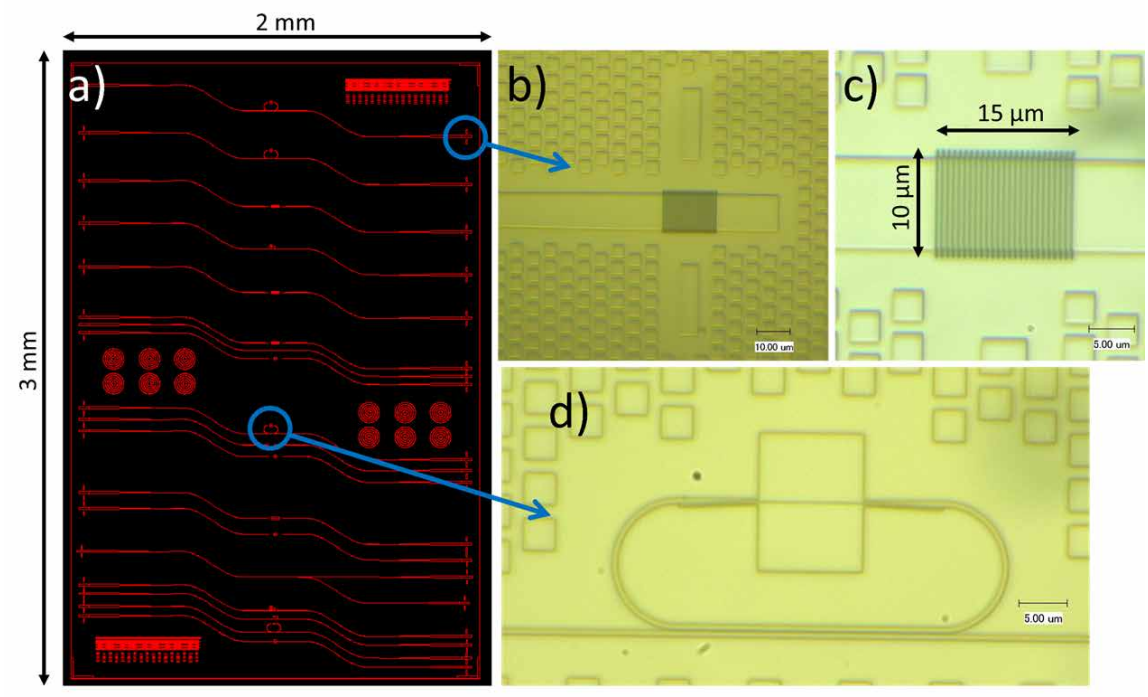

Fig. 5) a) Layout of the photonic chip. b) Fibre grating coupler with marker to align the optical fibre. c) Magnification of the fibre grating coupler. d) Ring resonator structure. a)

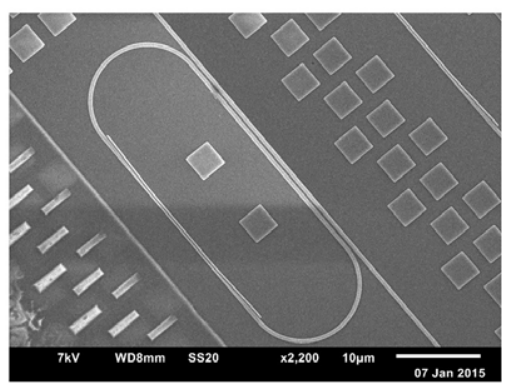

b)

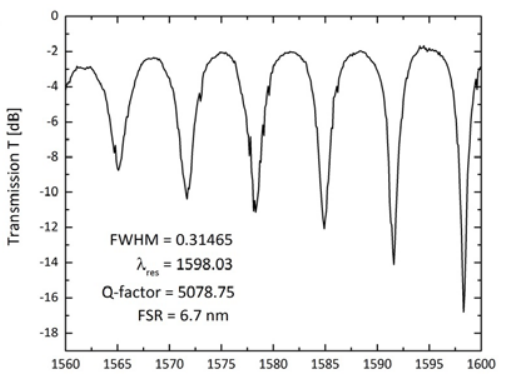

Fig. 6) a) Scanning-electron microscopic image of the top view of the fabricated ring resonator. b) Transmission spectra of a partially slotted ring resonator with EO polymer cladding. 
structures, and demonstrated, for the first time, the transmission spectrum of this ring resonator after deposition of an electro-optical polymer as cladding material. We obtained narrow transmission peaks with a full width at half maximum of about $\mathrm{FWHM}=0.3146 \mathrm{~nm}$ for a ring resonator fabricated on $200 \mathrm{~nm}$ silicon-on-insulator wafers using $248 \mathrm{~nm}$ DUV lithography. This value can be improved using advanced strip-toslot mode-converter design with logarithmic tapers instead of linearly tapered mode-converters. Another more challenging issue of the proposed concept is the implementation of EO polymers because of their thermal stability. This circumstance has to be investigated in more detail to find appropriate EO polymers for temperatures $>150^{\circ} \mathrm{C}$. However, our results are promising to build up future nano-photonic devices with silicon-organic hybrid technology. Future work should focus on optical loss reduction of the slot-waveguide to improve the $\mathrm{Q}$-factor of the ring resonator.

\section{Acknowledgements}

The authors would like to thank the German Federal Ministry of Education and Research (BMBF) for the financial support under contract no. $03 \mathrm{FH}$ 086PX2, the University of Applied Sciences Wildau (THWi), Germany, and the Ministry of Science, Technology and Culture of the federal state Brandenburg, Germany, for financial support. The authors would also like to thank Gero Göbel from the University of Applied Sciences Wildau (THWi), Germany, P. Prosposito, F. De Matteis, and R. De Angelis from the University of Rome "Tor Vergata", Italy, St. Meister and A. Al-Saadi from the Technical University Berlin, Germany, and L. Zimmermann, D. Knoll, D. Stolarek, J. Katzer, St. Lischke, H. Silz, B. Tillack, A. Mai, and W. Mehr from the Institute of High-Performance Microelectronics (IHP), Germany, for their encouragement and support in the framework of the Joint-Lab IHP-THWi.

\section{REFERENCES}

Alloatti L, Palmer R, Diebold S, Pahl KP, Chen B, Dinu R, Fournier M, Fedeli J, Zwick T, Freude W, Koos C, Leuthold J (2014) $100 \mathrm{GHz}$ silicon-organic hybrid modulator. Light Sci Appl 3(5):e173. doi: 10.1038/ Isa.2014.54

Almeida VR, Xu Q, Barrios CA, Lipson M (2004) Guiding and confining light in void nanostructure. Opt Lett 29(11):1209-1211. doi: 10.1364/OL.29.001209

Korn $D$, Jazbinsek $M$, Palmer $R$, Baier M, Alloatti $L$, Yu $H$, Bogaerts W, Lepage G, Verheyen P, Absil P, Guenter P, Koos C, Freude W, Leuthold J (2014) Electro-Optic Organic Crystal Silicon High-Speed Modulator. IEEE Photonics J 6(2):1-9. doi: 10.1109/JPHOT.2014.2314113

Steglich P, Mai C, Stolarek D, Lischke S, Kupijai S, Villringer C, Pulwer S, Heinrich F, Bauer J, Meister $S$, Knoll D, Casalboni M, Schrader S (2015a) Novel Ring Resonator Combining Strong Field Confinement With High Optical Quality Factor. IEEE Photon Technot Lett 9/LPT 2015.2456133

Steglich P, Padilla Michel Y, Villringer C, Dümecke $S$, Bauer JM, Heinrich F, Casalboni M, Schrader S (2015b) Design Optimization of Slot-Waveguides Covered with Organic Cladding Materials for Integrated Photonic Devices. In: Knaut M (ed) 16. Nachwuchswissenschaftlerkonferenz. Tagungsband, 16 Apr 2015. Berliner Wissenschaftsverlag, Berlin, ISBN: 978-3-8305-2044-3, pp 192-198

Steglich P, Villringer C, Dümecke S, Padilla Michel Y, Casalboni M, Schrader S (2015c) Silicon-on-Insulator Slot-waveguide Design Trade-offs. In: Proc PHOTOPTICS - 3rd Int Conf Photonics, Optics and Laser Technology, 12-14 Mar 2015, Berlin, ISBN: 978-989-758093-2, pp 47-52. doi: 10.5220/0005336200470052

\section{AUTHORS}

Patrick Steglich, M. Eng. Claus Villringer, M. Eng. Silvio Pulwer, M. Eng.

Dr. Joachim Bauer

Dr. Friedhelm Heinrich

Prof. Dr. Sigurd Schrader

Technische Hochschule Wildau

Research Group Photonics

Prof. Dr. Mauro Casalboni

University of Rome "Tor Vergata"

Department of Industrial Engineering

E-mail for correspondence:

patrick.steglich@th-wildau.de 